\title{
Locative Inversion in English: Implications of a Rating Study*
}

\section{Sara Holler \& Jutta M. Hartmann}

\section{Introduction}

Locative inversion (LI) in English as in (1) exhibits a number of interesting properties that are specific to inversion structures.

(1) Into the room walked John.

(Rochemont \& Culicover 1990, 70)

First of all, the subject appears post-verbally. Second, a prepositional or adverbial phrase appears in initial position. Third, LI has the discourse function of presentational focus. The inverted locative sets a scene onto which the subject is (re-)introduced (Bolinger 1971, 1977; Rochemont 1986; Bresnan 1994). This presentational focus is different from other inversion structures such as comparative inversion, where the subject receives contrastive focus (cf. Culicover \& Winkler 2008). Fourth, LI is available for a restricted verb class only; however, the exact classification is disputed. This paper concentrates on this aspect of LI. We investigate with a rating study whether LI is restricted to unaccusative verbs as proposed by Bresnan (1994) (see also L. Levin 1986), cf. (2), or whether unergative verbs can also appear in LI structures, as e.g. Levin \& Rappaport Hovav (1995) argue on the basis of a corpus study, cf. (3).

(2) a. Among the guests was sitting my friend Rose.

b. *Among the guests was knitting my friend Rose.

(Bresnan 1994, 78)

We thank S. Winkler, P. Culicover, M. Salzmann, A. Konietzko and the audience at Linguistic Evidence 2010 and the (Post)Doktorandenkolloquium 2011 for comments. Special thanks go to Janina Radó for help with the statistics and comments. This research was partially funded by the DFG (SFB 833, A7). 
(3) On the third floor worked two young women called Maryanne Thomson and Ava Brent, who ran the audio library and the print room. (B. Levin \& Rappaport Hovav 1995, 224, citing from: L. Colwin, Goodbye without Leaving)

Furthermore, Culicover \& Levine (2001) (henceforth C\&L) claim that LI is possible with unergative verbs as long as the post-verbal subject is heavy (in terms of length, complexity and stress) and shifted to the right. On the basis of two rating studies, the current paper investigates the following questions: First, is LI judged acceptable with both verb types? Second, does the heaviness of the subject play a crucial role for the acceptability of LI? Third, do unergative verbs require a right-adjacent subject? We show that $\mathrm{LI}$ is equally possible with unaccusative and unergative verbs independently of the heaviness of the subject. LI with unergative verbs does not require the subject to be right-adjacent. This implies that various previous syntactic analyses of LI are not adequate since the subject of unergative verbs cannot be base-generated post-verbally. We will outline possible alternatives. Nevertheless, it is clear that not all verbs are acceptable in LI. However, the restriction seems to be pragmatic (cf. Birner 1995 ) and related to the specific information structure of LI.

The paper is structured as follows. In section 2, we present two rating studies. The first one looked at unaccusative verbs, the second one at unergative verbs. In both studies, we investigated the effect of the word order and heaviness of the subject. In section 3, we will present the results. Section 4 discusses the implications of the findings for the syntactic analysis of LI and the possible information structural restrictions on the verb type. Section 5 concludes the paper.

\section{Experiment}

\section{$2.1 \quad$ Hypotheses}

C\&L distinguish Light and Heavy Inversion as two different syntactic phenomena. In Light Inversion the subject is base-generated post-verbally and remains in situ (see also Hoekstra \& Mulder 1990; Bresnan 1994). As only unaccusative verbs - but not unergative verbs - allow this base-generated word order, Light Inversion is restricted to unaccusative verbs (compare claim (4)). Light Inversion with an unaccusative versus an unergative verb is displayed in (5).

(4) Claim 1: Light Inversion only occurs with unaccusative verbs. 
(5) a. Into the room walked Robin. (unaccusative) (C\&L 2001, 292)

b. ${ }^{*}$ In the room slept Robin. (unergative) (C\&L 2001, 293)

Furthermore, the base-generated word order predicts that manner adverbs should not be allowed before the subject, as in (6) (see C\&L 2001, 292).

(6) a. Into the room walked Robin carefully.

b. * Into the room walked carefully Robin.

Heavy Inversion, where the subject is moved to the right via the syntactic subject position, is possible with both unaccusative and unergative verbs as given in (7). Thus, LI with unergatives is only possible with a heavy subject, $\mathrm{cf}$. (8a) vs. (8b), and it needs to be shifted to the right, cf. (8b) vs. (8c).

(7) Claim 2: Heavy Inversion occurs with both unaccusative and unergative verbs. For Heavy Inversion, the subject needs to be heavy and Heavy NP shifted.

(8) a. ${ }^{*}$ In the room slept Robin.

b. In the room slept fitfully the students in the class who had heard about the $[. .$.$] experiment that we were about to perpetrate.$

c. *In the room slept the students in the class who had heard about the [...] experiment that we were about to perpetrate fitfully.

(C\&L 2001, 293)

C\&L's observation of LI being a conflation of two different syntactic phenomena is in line with Levin \& Rappaport Hovav's (1995) corpus-based study, which also reports unergative verbs in LI. This observation was the starting point of our experimental investigations. However, the question is whether heaviness plays a crucial role in allowing unergative verbs in LI. A pilot study suggested that unaccusative and unergative verbs occur with both heavy and light subjects. This pilot study led us to our two hypotheses.

(9) Verb Class Hypothesis

$\mathrm{LI}$ is possible with both unergative and unaccusative verbs. 
(10) Extraposition Hypothesis

Extraposition (in LI) applies whenever the subject is heavy. ${ }^{1}$

(9) claims that LI can apply with unergatives regardless of the heaviness of the subject. We expect both verb types to be equally acceptable in (11). ${ }^{2}$

(11) a. In the dormitory arrived twenty students quite happily. (unacc.)

b. In the dormitory slept twenty students quite happily. (unerg.)

The second hypothesis assumes extraposition of heavy subjects independently of the verb class: heavy subjects have to be extraposed with both verb types. Accordingly, (12a) and (13a) are expected to be unacceptable whereas (12b) and (13b) are expected to be acceptable. Thus, the behaviour of both unergative and unaccusative verbs combined with a heavy subject should be the same.

(12) a. Inside appeared various colourful fish which my uncle had recently bought from a fish breeder very slowly.

b. Inside appeared very slowly various colourful fish which my uncle had recently bought from a fish breeder.

(13) a. Inside swam various colourful fish which my uncle had recently bought from a fish breeder very slowly.

b. Inside swam very slowly various colourful fish which my uncle had recently bought from a fish breeder.

We conducted two rating studies. The first one investigated LI with unaccusative verbs, the second one LI with unergative verbs. Both studies manipulated the factors heaviness and extraposition, leading to the four conditions given in (14).
a. Light-intraposed: $\quad \mathrm{PP}-$ verb - lightNP $-\mathrm{AdvP}$
b. Light-extraposed: $\mathrm{PP}-$ verb-AdvP - lightNP

1. By "extraposition", we refer to the word order with the subject appearing at the very right edge of the sentence, independent of any specific syntactic analysis.

2. According to the pseudo-passive test arrived is an unaccusative verb whereas slept is unergative (Perlmutter \& Postal 1984, 101):

(i) * The airport was arrived at by our uncle.

(ii) A bed was slept in by a girl. 


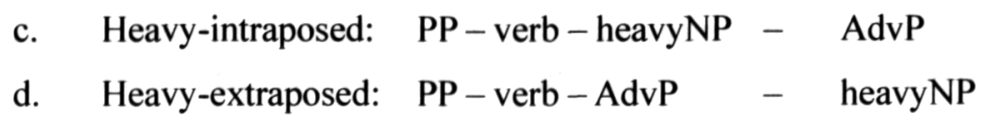

\subsection{Materials}

In order to create a stark contrast between light and heavy subjects, light subjects were kept as short and simple as possible. Following Arnold et al.'s (2000) definition of heaviness, light subjects consisted of two words and four syllables. ${ }^{3}$ We chose numerals to precede them. By contrast, heavy subjects were made up of 13 to 16 words and 18 to 25 syllables. The modifier which was added to the heavy subjects included not only a numeral but also an adjective. Moreover, for syntactic complexity, heavy subjects contained a relative clause. Two examples of heavy subjects are given below:

(15) twenty lazy students who had heard about the researchers' important social psych experiment

(16) numerous hideous trolls which looked rather inhuman with their oversized heads and noses

Manner adverbs (AdvP), which mark the right edge of the verb phrase, served the purpose of comparing extraposed word order (PP V AdvP NP) and intraposed word order (PP V NP AdvP). Manner adverbs were combined with adverbs of degree (examples are very slowly or quite cheerfully). As the light NPs and the AdvPs were equal in length, it was entirely left up to the grammar to determine when to shift the subject.

Concerning the selection of unaccusative versus unergative verbs, we followed the basic classification from Perlmutter (1978). According to him, subjects of unaccusatives are base-generated below the verb as its complement, while subjects of unergatives are base-generated higher than the verb in the verb's subject position. This means that unaccusative verbs have a direct internal argument, which functions as the theme or patient, whereas unergatives have an external argument, which receives an agent role. The verbs used in our experiments were all tested with the so-called pseudo-passive test (cf. Perlmutter \& Postal 1984), which is the most reliable test for the distinction of the two

3. Peter Culicover (p.c.) pointed out that intonation can make a noun phrase heavy and thus improve the extraposed word order with light subjects. However, the interesting cases are light subjects with intraposed word order. Thus, the lack of intonation in our study is not a problem. 
verb types in English. Since unaccusatives cannot occur in pseudo-passives, see (17), only those verbs that passed the test were classified as unergatives.

(17) a. * The bridge was existed under by the trolls.

b. * The dome was collapsed under by the model. (Perlmutter \& Postal, 1984, 100f)

In (18), pseudo-passivization with unergative verbs is illustrated.

(18) a. The bed was slept in by the shah.

b. The bed was jumped on by the children.

(Perlmutter \& Postal, 1984, 100f)

The first study examined LI with unaccusatives and the second one LI with unergatives. The unaccusative and unergative verbs used in this experiment were based on a list by Perlmutter (1978) as given in Kuno \& Takami (2004). The verbs in the test sentences were all used in the simple past form. Twelve lexical variants were written, of which four sentences were based on examples given in the literature. The experimental items were distributed on four lists following a Latin square design. Each lexical variant was presented once per list in one of the four conditions. Each condition was tested three times per list. A sample item with both verb types (unaccusative: appeared, unergative: swam) is given in (19). ${ }^{4}$

(19) a. Light-intraposed:

Inside appeared/swam [various fish] [very slowly]. ${ }^{5}$

b. Light-extraposed:

Inside appeared/swam [very slowly] [various fish].

c. Heavy-intraposed:

Inside appeared/swam [various colourful fish which my uncle had recently bought from a fish breeder][very slowly].

4. This example is based on B. Levin \& Rappaport Hovav 1995, 257, citing from: J. Olshan, The Waterline, 177.

5. P. Culicover pointed out that the VP adverbials in our items could also be parenthetical/afterthoughts. However, if participants had interpreted adverbials as parenthetical, we would expect the same effect for heavy and light subjects - this effect did not turn up in our experiments. 


\section{d. Heavy-extraposed:}

Inside appeared/swam [very slowly][various colourful fish which my uncle had recently bought from a fish breeder].

In addition to the experimental items, 36 filler sentences were added. Roughly one third were rather unacceptable sentences. The fillers included four sentences with LI and transitive verbs, which are generally assumed not to be able to undergo LI (cf. Bresnan 1994 among others; for an exception see C\&L). The filler sentences (20) were thus expected to receive very low ratings (20c,d are based on Bresnan 1994, 77).

\section{(20) Fillers: LI with transitives}

a. Among the guests ate roast beef several guys.

b. In the office saw a note two employers.

c. In the rainforest found the reclusive bird thirteen lucky hikers who actually just wanted to have adventurous and exciting holidays.

d. On the corner drank beer numerous teenaged boys who were ready for a weekend full of fun and parties.

\subsection{Participants and Procedure}

Twenty-seven native speakers of English took part in the first study, twentyfour native speakers in the second one. They were randomly assigned to the lists, and each questionnaire was judged six or seven times. Speakers of both British English and American English participated. All participants were naïve to the purpose of the study. They received the questionnaires via e-mail, and filled them in within 15 days.

The participants' task was to read the sentences carefully and to rate them on a scale of one (= unnatural and hard to understand) to seven (= natural and highly acceptable). Participants were asked to rely on their intuitions of what sounds good. They were also told to make use of the whole scale and not to go back to single sentences to change their ratings. The questionnaires started with written instructions and an example. At least five filler sentences appeared on each list before the first test sentence. 


\section{Results}

\subsection{Results Experiment 1: Unaccusatives}

Mean ratings per condition are given in table 1 and figure 1. Ratings were analysed in two repeated measures ANOVAs with subjects and with items as random effects. The effect of heaviness was fully significant by subjects but only marginally by items $\left(\mathrm{F}_{1}(1,26)=4.483, \mathrm{p}=0.044 ; \mathrm{F}_{2}(1,11)=4.483, \mathrm{p}=0.058\right)$. The effect of extraposition only approached significance in the subjects analysis $\left(F_{1}(1,26)=3.121, p=0.089 ; F_{2}(1,11)=1.056, p=0.326\right)$. There was a significant interaction between extraposition and heaviness $\left(F_{1}(1,26)=19.901, p=0.000\right.$; $\left.\mathrm{F}_{2}(1,11)=16.402, \mathrm{p}=0.002\right)$, indicating that extraposition affects heavy and light subjects differently. We used planned contrasts to test the specific predictions. LI with heavy subjects received significantly higher ratings in the extraposed word order than in the intraposed order $\left(\mathrm{t}_{1}(26)=-3.969, \mathrm{p}=0.001\right.$; $\left.\mathrm{t}_{2}(11)=-3.969, \mathrm{p}=0.010\right)$. Intraposed heavy subjects were rated rather low.

Table 1. Mean ratings per condition with unaccusative verbs ${ }^{6}$

\begin{tabular}{llll}
\hline & Condition & Rating & Example $^{6}$ \\
\hline 1 & light-intraposed & 3.59 & $\begin{array}{l}\text { Under the stairs existed numerous trolls quite } \\
\text { cheerfully. }\end{array}$ \\
2 & light-extraposed & 3.05 & $\begin{array}{l}\text { Under the stairs existed quite cheerfully numerous } \\
\text { trolls. }\end{array}$ \\
3 & heavy-intraposed & 2.36 & $\begin{array}{l}\text { Under the stairs existed numerous hideous trolls } \\
\text { which looked rather inhuman with their oversized } \\
\text { ears and noses quite cheerfully. }\end{array}$ \\
4 & heavy-extraposed & 3.5 & $\begin{array}{l}\text { Under the stairs existed quite cheerfully numerous } \\
\text { hideous trolls which looked rather inhuman with } \\
\text { their oversized ears and noses. }\end{array}$ \\
\hline
\end{tabular}

6. Note that the examples in table 1 and table 2 are for illustration purposes only. The ratings are mean values for all experimental items in this condition. 


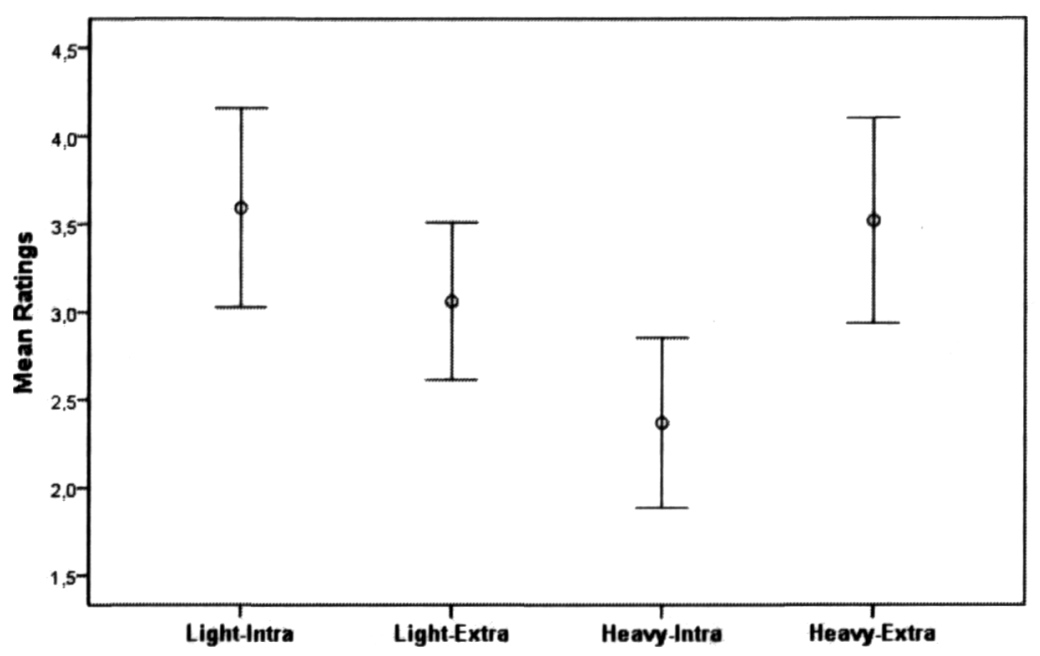

Figure 1. Mean ratings per condition for experiment 1

The pattern was reversed with light subjects: the intraposed word order was rated higher than the extraposed word order $\left(t_{1}(26)=2.418, p=0.023 ; t_{2}(11)=1.562\right.$, $\mathrm{p}=0.146$ ) though the difference was not as big as with heavy subjects, and was only significant by subjects. Sentences with light subjects and extraposed order were rated worse, but not as bad as LI with heavy subjects with intraposed word order.

\subsection{Results Experiment 2: Unergatives}

Mean ratings per condition are given in table 2 and figure 2 .

Table 2. Mean ratings per condition with unergative verbs

\begin{tabular}{|c|c|c|c|}
\hline & Condition & Rating & Example \\
\hline 1 & light-intraposed & 3.86 & $\begin{array}{l}\text { Under the stairs danced numerous trolls quite cheer- } \\
\text { fully. }\end{array}$ \\
\hline 2 & light-extraposed & 3.56 & $\begin{array}{l}\text { Under the stairs danced quite cheerfully numerous } \\
\text { trolls. }\end{array}$ \\
\hline 3 & heavy-intraposed & 2.70 & $\begin{array}{l}\text { Under the stairs danced numerous hideous trolls which } \\
\text { looked rather inhuman with their oversized ears and } \\
\text { noses quite cheerfully. }\end{array}$ \\
\hline 4 & heavy-extraposed & 3.97 & $\begin{array}{l}\text { Under the stairs danced quite cheerfully numerous } \\
\text { hideous trolls which looked rather inhuman with their } \\
\text { oversized ears and noses. }\end{array}$ \\
\hline
\end{tabular}




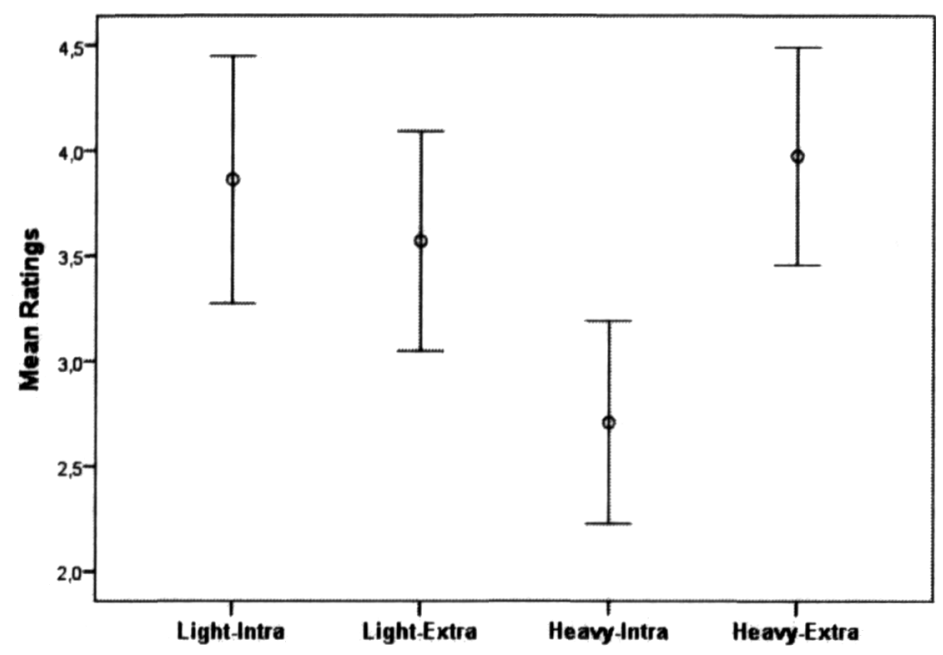

Figure 2. Mean ratings per condition for experiment 2

Ratings were analysed in two repeated measures ANOVAs with subjects and with items as random effects. The effect of extraposition was significant $\left(\mathrm{F}_{1}(1,23)=4.632, \mathrm{p}=0.042 ; \mathrm{F}_{2}(1,11)=10.703, \mathrm{p}=0.007\right)$ whereas the effect of heaviness was marginal both by subjects and by items $\left(\mathrm{F}_{1}\right.$ $\left.(1,23)=3.232, p=0.085 ; F_{2}(1,11)=3.550 ; p=0.086\right)$. There was a significant interaction between extraposition and heaviness $\left(F_{1}(1,23)=33.455, p=0.000\right.$; $\left.F_{2}(1,11)=10.170, p=0.009\right)$. This shows that heavy and light subjects are affected differently by extraposition. Planned contrasts were used to test the specific predictions. The ratings for LI with heavy subjects were significantly higher with extraposed than with intraposed word order $\left(t_{1}(23)=-4.247\right.$, $\left.\mathrm{p}=0.000 ; \mathrm{t}_{2}(11)=-3.685, \mathrm{p}=0.010\right)$. With light subjects, there was no significant difference between extraposed and intraposed word order $\left(t_{1}(23)=1.309\right.$, $\left.\mathrm{p}=0.203 ; \mathrm{t}_{2}(11)=1.367, \mathrm{p}=0.199\right)$. LI with light, extraposed subjects is still rated higher than LI with heavy non-extraposed subjects.

\subsection{Summary of the Results}

The most important findings of our results are: (i) LI is equally possible with both unaccusative and unergative verbs: first, the pattern was the same in both experiments; second, the participants of the two experiments appeared to have used the same scales, which is indicated by very similar means for individual sentences, as well as for the general means of the fillers. (ii) Not only unaccusative verbs but also unergative verbs allow the intraposed word order with 
light subjects, i.e. the subject in LI with unergative verbs does not need to be extraposed (as long as the adverbial is equal in length). (iii) Heavy subjects have to be extraposed. Heaviness plays a crucial role for word order, but not for the acceptability of the different verb classes. Our results do not support C\&L's first claim, namely that Light Inversion only occurs with unaccusative verbs. Intraposed subjects are also possible with unergative verbs. C\&L's second claim that Heavy Inversion occurs both with unaccusative and unergative verbs is supported by our results.

Note that the highest average rating for experimental sentences was only 3.97 on a seven-point scale even though the participants used the whole range of the scale: Some of the fillers were designed to mark the top, the bottom and the middle of the scale. There are probably two related reasons for the low ratings of the experimental items. Firstly, LI is limited to certain informationstructurally defined contexts. As the sentences were presented without context, the information structural requirements of LI are not satisfied. Additionally, the sentences contained a post-verbal adverbial, which makes it even more difficult to construe an appropriate context. Nevertheless, the contrasts between the individual conditions as well as the similarities between the two experiments remain significant and as such, we take our results to be reliable.

\section{Implications of the Results}

In this section, we discuss the implications of the findings of our study both for the syntactic analysis as well as for the restrictions on verb classes in LI.

\subsection{Syntax of LI}

The syntactic analysis of LI in the generative grammar framework can be divided into two major approaches: (i) Low subject accounts and (ii) subject extraposition analyses. As the names suggest, the main distinguishing feature in this classification is the position of the thematic subject. The low subject accounts have to be further subdivided into PP movement accounts and silent proform accounts. We will see below that our results are problematic for both low subject approaches (for a recent summary of the advantages and problems in general see Salzmann 2009). The second class of approaches fares slightly better, but the subject extraposition analyses are available only for a subclass of LI cases. In search of a better analysis, we look at the verb movement account as proposed in Salzmann (2009). This approach can handle the data in our experiment. However, the predictions of the proposal need to be tested empirically. 
Finally, we present a proposal for a possible alternative account in terms of PF movement. Whether this approach is feasible requires further data.

\subsubsection{Low subject accounts}

The class of low subject accounts can be further divided into PP movement and silent pro-form analyses. In the PP movement approaches (see Hoekstra \& Mulder 1990; Bresnan 1994; Collins 1997; den Dikken 2006; Broekhuis 2008; Hartmann 2008; Light Inversion in C\&L), a post-verbal PP moves to the subject position (and possibly beyond) to satisfy the EPP. In the silent proform analyses (see Postal 1977, 2004; Coopmans 1989) the subject position is filled by a silent counterpart of the pro-form there in English. Both approaches crucially rely on the thematic subject being base-generated as a complement of the verb, cf. the tree structures in (21) and (22). This is arguably true for unaccusative verbs.

(21)

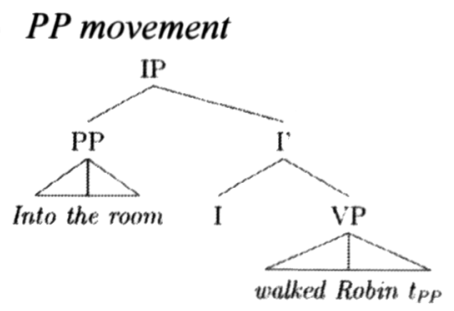

(22) Silent pro-form analysis

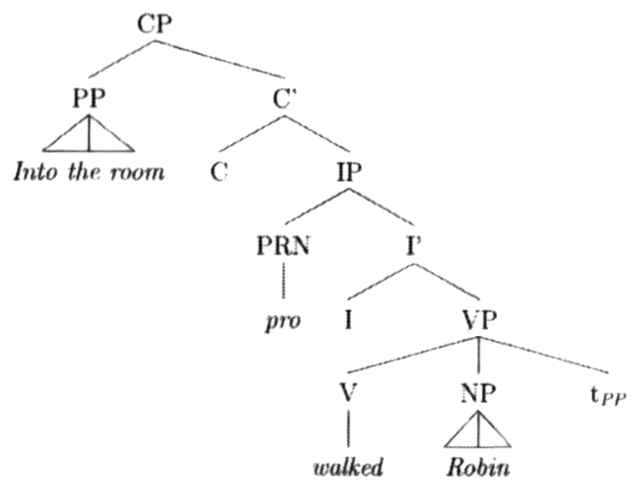

However, both structures are incompatible with unergative verbs: the thematic subject is base-generated higher than the verb (Perlmutter 1978; Bowers 2001). As a result, the intraposed word order for unergative $P P$ verb-subject-adverbial cannot be a base-generated word order. 
One attempt to account for the possibility of unergative verbs in LI structures with a PP movement account is the proposal by Hoekstra \& Mulder (1990). They argue that unergative verbs can be made unaccusative by the presence of a directional/result PP. However, the argumentation is circular for English LI: They claim that the construction only allows for unaccusative verbs and therefore the verbs occurring in the structure have to be unaccusative. The examples in the literature and those used in the experiment reported here, lack a directional/result PP. Thus, the crucial ingredient for unaccusativization is missing. So far, we do not see any other argument for this approach - especially because other tests for unaccusativity are not applicable in English (e.g. auxiliary selection, impersonal passives) or cannot be combined with LI (e.g. past participle as nominal modifier, pseudo-passive test).

\subsubsection{Subject extraposition}

The major exponent of the subject extraposition account is C\&L's proposal for Heavy Inversion. According to their analysis, a heavy subject can extrapose to the right from the Spec,IP position, cf. (23). The trace in the subject position is licensed by a prepositional/adverbial phrase adjoined to IP. This analysis is certainly possible for the cases of heavy extraposed subjects. And we follow this analysis for these cases (for arguments that LI with heavy subjects is a separate phenomenon, see $C \& L$ ). However, the analysis is not available for the intraposed word order with unergative verbs and light subjects. An adverbial can appear to the right of the subject, which is unexpected in the extraposition analysis.

\subsubsection{Verb movement account}

Based on a previous analysis by Rochemont \& Culicover (1990), Salzmann (2009) proposes that the word order PP V NP (ADV) with unergative verbs is derived from verb movement: the verb moves across the subject to a head above $\mathrm{vP}$, which he takes to be an aspectual projection. This verb movement is only available in LI because it serves the requirement for the subject to be focused. 
(23) Heavy Inversion (cf. C\&L 2001, 294)

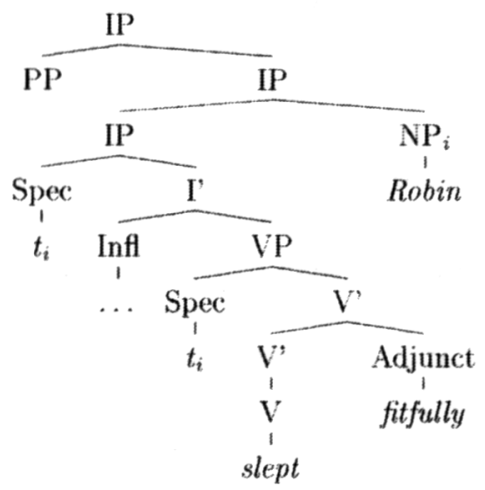

(24) Salzmann (2009)

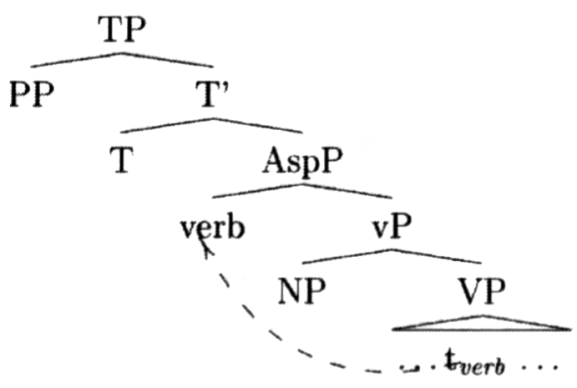

Salzmann (2009) provides evidence for this verb movement from the position of adverbials. VP adverbials can follow the verb in LI, which is otherwise not possible, (1) (Salzmann 2009, citing books.google.de/books?isbn $=1579788335$ John Oyer).

(25) Behind Luther's Word stood always the concept of a historical revelation which had been recorded in the Scriptures.

However, these examples are taken from the internet and it is not entirely clear whether this is an acceptable pattern only occurring in LI. An additional rating study should clarify the issue. From a theoretical point of view, the question arises of why this movement occurs only in LI and how it can be triggered. In Salzmann's analysis, the movement of the verb is driven by two forces that add up in LI: (i) feature-checking of aspectual properties of the verb and (ii) repair-driven movement (in the sense of Heck \& Müller 2007) of the verb to 
allow the subject to be right-aligned and thus, occupy the default focus position in the sentence. This is implemented with different rankings in optimality theoretical (henceforth OT) terms. Technically this means that the constraint AlignFocus is ranked higher than the constraint NoLexMvt, which usually bans verb movement.

\subsubsection{PF Movement}

Göbbel (2010, to appear) argues for PF movement of phrases in relative clause extraposition, cf. (26), PP extraposition, cf. (27), Heavy-NP Shift, cf. (28) and CP shift, cf. (29).

(26) a. Last night, a man we'd never seen before arrived. >

b. Last night, a man arrived who we'd never seen before: (EX-Rel)

(27) a. I read a magazine about Turner on Monday. >

b. I read a magazine on Monday about Turner. (EX-PP)

(28) a. Bill explained Newton's law of gravitation to Mary. $>$

b. Bill explained to Mary Newton's law of gravitation. (HNPS)

(29) a. Bill explained why he was late for work to Mary. >

b. Bill explained to Mary why he was late for work. (CP shift)

In an OT-based analysis of various phonological constraints, Göbbel argues that the word orders in the b-examples in $(26)-(29)$ are optimal candidates at $\mathrm{PF}$, whilst not being faithful to the syntactic representation. In a nutshell, by reordering the syntactic constituents, the phonological representation gains in balance. The constraint BinIP given in (30) favours the b-sentences over the a-sentences in HNPS and CP shift.

(30) Bin IP: An IP contains two prosodic phrases.

(31) Excited about Greece and its cultural heritage,

a. (he donated a vase) (that shows Zeus and Apollo fighting) (to a museum)

b. (he donated to a museum) (a vase that shows Zeus and Apollo fighting) 
What did you say about Mary?

a. (She mentioned) (that her jeans were dirty) (to Bill)

b. (She mentioned to Bill) (that her jeans were dirty)

However, there is a crucial difference between the structures that Göbbel (2010) investigates and the LI cases here: while Göbbel investigates the deaccentuation of old material on the right edge, the constituents on the right edge in LI are typically new information (cf. Birner \& Ward 1998) and are assigned presentational focus (see below). Yet it is in principle possible to transfer the core ideas of such reordering at PF to the LI cases with unergative and unaccusative verbs. Note, however, that the phonological reordering in English is usually highly restricted: in most cases, the word order is strictly SVO. Therefore, it is crucial to exclude overgeneration. This is feasible on the following assumptions: (i) In the syntax, the subject remains low in the $\mathrm{vP}$ both with unergative and unaccusative verbs. (ii) The PP is base-generated or moved to the initial position. (iii) The violation of the EPP is possible because the subject needs to remain low to satisfy information structural restrictions in the syntax. This analysis implies that focus and realization of intonation are independent to some degree. The subject remains low to satisfy information structural restrictions, but it is pronounced and stressed at the end of the phrase for phonological reasons. In the phonological phrasing of the $\mathrm{vP}$, the word order of the verb and the subject is rearranged to satisfy the constraints on heaviness and newness. An open question is whether this PF account could in principle work for transitive verbs as well. On the one hand, some transitive verbs seem possible in LI as long as they are not "semantically transitive". On the other hand, the syntax of transitive verbs differs from the syntax of intransitive verbs, which in turn might affect the possible reordering at PF. Further data is necessary to determine the adequacy of this approach.

\subsection{Verb Classes and Information Structure}

The results of our studies show that the distinction of unergative vs. unaccusative verbs is not relevant for the licensing of LI in English. Nevertheless, following the investigations on verbs in LI in the literature, it is still clear that not all verbs are possible in LI. In this section, we first look at the restriction on transitive verbs. Based on the data of $\mathrm{C} \& \mathrm{~L}$, we tentatively conclude that the restriction on transitive verbs is not a syntactic restriction. Instead, we suggest in line with Birner (1995) that whether a verb can or cannot occur in LI is restricted by the information structure (IS) of LI. Even though we follow the 
main intuition underlying Birner's proposal, the exact nature of the IS restriction both on LI and the verb classes is more difficult to grasp and needs to be based on a broader set of experimental data.

\subsubsection{Transitive Verbs in Locative Inversion}

It has been reported repeatedly that transitive verbs are impossible in LI structures (cf. Rochemont 1978, Bresnan 1994 among others). Our study supports this finding: the filler sentences with LI and transitive verbs given in (33) were rated very low (Mean rating experiment 1: 1.98; Mean rating experiment 2: $1.81)$.

(33) a. Among the guests ate roast beef several guys.

b. In the office saw a note two employers.

c. In the rainforest found the reclusive bird thirteen lucky hikers who actually just wanted to have adventurous and exciting holidays.

(based on Bresnan 1994, 77)

d. On the corner drank beer numerous teenaged boys who were ready for a weekend full of fun and parties. (based on Bresnan 1994, 78)

By contrast, C\&L (2001) present examples with Heavy Inversion and transitive verbs that they rate acceptable, see (34) and (35).

(34) [In the backyard] were sunning themselves [a group of the largest iguanas that had ever [been] seen in Ohio].

(C\&L, 2001, 308)

(35) The economist predicted that [at that precise moment] would turn the corner [the economics of half a dozen South American nations].

(C\&L, 2001, 308)

Syntactically, these verbs should still be analysed as transitive verbs. Thus, the restriction on transitive verbs cannot be ruled out on syntactic grounds. The crucial difference between these examples and our filler sentences is that the direct object does not introduce a further event participant in C\&L's examples. If this is indeed the relevant difference, this supports an approach in which the information structural restrictions on LI are decisive: a further event participant following the verb cannot be accommodated to the presentational function (in the sense of Bolinger 1977) of the structure. Thus, we suggest seeking an explanation for the restriction on verb classes in LI in the information structure of LI. 


\subsubsection{Information Structural Requirements of $L I$}

According to the literature, three information structural restrictions on LI can be formulated (see Bolinger 1977; Rochemont 1986; Birner 1992, 1994; Levin \& Rappaport Hovav 1995; among others): (i) The preposed PP functions as a scene setter, while (ii) the subject NP is (re-)introduced onto this scene receiving presentational focus. ${ }^{7}$ (iii) Only verbs that can support the function of presentational focus occur in LI.

The verb serves to support the presentational function of the construction. Birner (1995) suggests that verbs that can occur in LI need to be 'inherently light'. By this she means that the verb can be predicted from the first constituent and does not contribute any new information. This is clear for the example in (36) - the verb preach is predictable from the pulpit. But this is less clear for the examples in (37) - why should the verb melt be more predictable from sticky hands than from the streets of Chicago?

(36) From this pulpit preached no less a person than Cotton Mather. (Birner 1995, 253)

(37) a * On the streets of Chicago melted a lot of snow.

b. In Maria's sticky hand melted a chocolate-chip ice cream cone. (Birner, 1995, 253)

We argue that the unacceptability of the example in (37a) does not (only) depend on the predictability of the verb, but that it is rather caused by the choice of a wrong subject. The subject a lot of snow cannot receive presentational focus. When snow melts, it usually disappears and it is difficult to accommodate

7. We adopt Rochemont's (1986: 52) definition of presentational focus here. An expression $\mathbf{P}$ is a presentational focus in a discourse if $P$ is not c-construable (i.e. it does not have a semantic antecedent in the discourse). Applying this definition to LI constructions means that the subject NP should not be accessible or given in the context. 
the presentation of snow in such a situation. ${ }^{8}$ The example can be improved in the following ways: ${ }^{9}$

\section{a. On the streets of Chicago melted an iceberg.}

b. Out in the Chicago streets melted the very handful of snow containing the diamonds that they were looking for.

From our point of view, the crucial change that is achieved in these examples is that something is presented on the scene: an iceberg can be imagined as something that is melting without disappearing at the same time. In (38b), with the melting of the snow, the diamonds appear on the scene instead. These examples show that the problem with (37a) is not the predictability from the prepositional phrase, but the presentability of the post-verbal noun phrase. (37a) cannot therefore fulfill the information structural requirements of locative inversion. In order to investigate the information structural requirements on the verb, it is necessary to make sure that the requirements on the PP and the post-verbal subject are fulfilled in the first place. These requirements will be considered, and we will then come back to the question of the verb types in LI.

The information structural requirements of LI can be described as follows: the preposed PP enables LI to have the discourse function of presentational focus since it sets a scene onto which the subject referent is (re)introduced (Bolinger 1971, 1977; Rochemont 1986; Bresnan 1994). Both requirements, the scene setting function of the PP and the presentation of the subject, have to be fulfilled to make LI felicitous. Consider (39).

8. One can interpret the examples in (i) from Bolinger $(1977,96,99)$ similarly.

(i) a. Slowly dissolving was a mass of ectoplasm.

b. Away sailed an enormous ship.

A mass of ectoplasm that is slowly dissolving is still presentable. Similarly, an enormous ship is surprising enough to be presented even when the direction of the ship is towards the horizon, where it potentially disappears from view. Similarly in the example On the streets of Chicago finally melted all that dirty and ugly grey snow (provided by an anonymous reviewer), the introduced snow adds to the overall picture, even though the snow potentially disappears from view.

9. We thank K. Griffin for providing example (37a) and an anonymous reviewer for (38b) who also suggested that the problem with (37a) is the lack of presentation of the post-verbal NP. 
(39) A: I'm looking for my friend Rose.

B: \#Among the guests of honor was sitting Rose.

C: Rose was sitting among the guests of honor.

(Bresnan 1994, 85)

Speaker A's utterance is odd: Firstly, as Rose has just been mentioned by what has been said by speaker A, it is unnatural to reintroduce her on a scene by speaker B. Moreover, the scene among the guests of honor has not been set in the preceding sentence but is rather newly introduced.

Birner (1994) explains this effect with the information-packing function of inversion: Following Horn (1984) and Prince (1992) she argues that in inversion structures, the preposed element must not be newer in the discourse than the postponed element. Thus, the relationship between the PP and the subject is crucial for the felicity of a LI structure. The following examples from the British National Corpus and Doris Lessings's The Grass is Singing illustrate this claim. In both examples the PP has been given in the sentence preceding the LI structure but the subject is discourse-new. ${ }^{10}$

(40) The Primitive Methodist chapel was built in 1837 and then rebuilt on the same site in 1887. Near the chapel stands the church institute, a Gothicstyle building built in 1844. (BNC text="C93" $\mathrm{n}=$ "1527")

(41) When he reached the house at last, he saw, as he approached through the bush, six glittering bicycles leaning against the wall. And in front of the house, under the trees, stood six native policemen, and among them the native Moses, his hands linked in front of them. (Doris Lessing, 2007, 15)

We therefore claim that the discourse status of the preposed locative and that of the subject NP both play a crucial role for the felicity of a LI construction.

Coming back to the IS requirements on the verb, we would like to propose that the verb in LI has to function as an adequate link between the PP and the noun phrase. The core meaning of the verb in LI links the PP and NP in such a way that the PP can introduce the scene on which the noun phrase is presented. This is straightforward for the verb $b e$, verbs of appearance and locative verbs

10. It is not entirely clear whether the crucial factor is the discourse-status (new, old) of the PP and the subject, or rather if the PP needs to establish a link to the description of the preceding discourse in order to anchor the ground on which the post-verbal noun phrase is presented (see Cheng 2003 for discussion). 
like stand or sit. The more additional meaning a verb has (e.g. manner of appearance, manner of location, change of state), the less likely it is to occur in LI. ${ }^{11}$ More work is required here.

In sum, Birner's requirement for the verb to be light in LI therefore seems to be a step in the right direction, but more data would be needed to define the notion of "lightness" and to investigate our hypothesis.

\section{Conclusion}

In this paper, we have presented results from two rating studies about the possibility of unergative and unaccusative verbs in LI in English. Our results show that both classes are equally possible, independent of the post-verbal subject being heavy or light. If a subject is heavy, it has to be extraposed with both types of verbs. If the subject is light, it can occur in an intraposed position, preceding a manner adverbial. Current syntactic analyses of LI cannot account for the possibility of intraposed word order with unergative verbs. We have presented two alternative theories, Salzmann (2009) and our own suggestions regarding PF movement, to account for the observed data. More work is needed to distinguish these proposals.

Our results show that the distinction between unergative and unaccusative verbs is not relevant for the restrictions on verb classes in LI. In order to account for the restrictions reported in the literature, a different approach is needed. We hypothesize that such a restriction on verbs in LI has to be closely linked to the information structural requirements of LI.

\section{References}

Arnold, Jennifer E., Thomas Wasow, Anthony Losongeo \& Ryan Gintstrom

2000 Heaviness vs. newness: The effects of structural complexity and discourse status on constituent ordering. Language 76: 28-55.

Birner, Betty

1992 The discourse function of inversion in English. Doctoral Dissertation, Northwestern University, Evanston III.

Birner, Betty

1994 Information status and word order: An analysis of English inversion. Language 70: 733-59.

11. For a discussion of change-of-state verbs in LI, see Landau (2010, 121-123). 
Birner, Betty

1995 Pragmatic constraints on the verb in English inversion. Lingua 97: 233256.

Birner, Betty \& Gregory Ward

1998 Information Status and Noncanonical Word Order in English. Amsterdam/Philadelphia: John Benjamins.

Bolinger, Dwight

1971 A further note on the nominal in the progressive. Linguistic Inquiry 2: 584-586.

Bolinger, Dwight

1977 Meaning and Form. London: Longman.

Bowers, John

2001 Predication. In: Mark Baltin and Chris Collins (eds.), The Handbook of Contemporary Syntactic Theory, 299-333. Malden, MA/ Oxford: Blackwell.

Bresnan, Joan W.

1994 Locative inversion and the architecture of Universal Grammar. Language 70 (1): 72-131.

British National Corpus (BNC)

2001 Version 2 (world edition), Oxford University Computing Services on behalf of the BNC Consortium.

Broekhuis, Hans

2008 Derivations and Evaluations: Object Shift in the Germanic Languages.

Berlin/New York: Mouton de Gruyter.

Cheng, Rong

2003 English Inversion: A Ground-before-Figure Construction. Berlin, New York: Mouton de Gruyter.

Collins, Chris

1997 Local Economy. Cambridge, MA: MIT Press.

Coopmans, Peter

1989 Where stylistic and syntactic processes meet: Locative inversion in English. Language 65 (4): 738-751.

Culicover, Peter W. \& Robert D. Levine

2001 Stylistic inversion in English: A reconsideration. Natural Language and Linguistic Theory 19: 283-310.

Culicover, Peter W. \& Susanne Winkler

2008 English Focus Inversion. Journal of Linguistics 44: 625-658.

Den Dikken, Marcel

2006 Relators and Linkers: the Syntax of Predication, Predicate Inversion, and Copulas. Cambridge, MA: The MIT Press. 
Göbbel, Edward

2010 Prosodically-conditioned rightward movement: The case of relative clauses. Talk presented at "Focus, Contrast and Givenness in Interaction with Extraction and Deletion."

Göbbel, Edward

to appear Extraposition of defocused and light PPs in English. In: Manfred Sailer, Heike Walker, and Gert Webelhuth (eds.), Rightward Movement From a Cross-Linguistic Perspective. Amsterdam: John Benjamins.

Hartmann, Jutta M.

2008 Expletives in Existentials: English there and German da. Utrecht: LOT. Heck, Fabian \& Gereon Müller

2007 Derivational optimization of wh-movement. Linguistic Analysis 33 (1-2): 97-148.

Hoekstra, Teun \& Rene Mulder

1990 Unergatives as copular verbs: Locational and existential predication. The Linguistic Review 7: 1-79.

Horn, Laurence R.

1984 Toward a new taxonomy for pragmatic inference: Q-based and R-based implicature. In: Deborah Schiffrin (ed.), Meaning, Form, and Use in Context: Linguistic Applications, 11-42. Washington DC: Georgetown University Press.

Kuno, Susumu \& Ken-Ichi Takami

2004 Functional Constraints in Grammar on the Unergative-unaccusative Distinction. Amsterdam/Philadelphia: John Benjamins.

Landau, Idan

2010 The Locative Syntax of Experiencers. Cambridge, MAss.; MIT Press.

Levin, Beth \& Malka Rappaport Hovav

1995 Unaccusativity at the Syntax-Lexical Semantics Interface. Cambridge, MA: MIT Press.

Levin, Lorraine

1986 Operations on lexical forms: Unaccusative rules in Germanic languages. Dissertation, MIT.

Lessing, Doris

2007 The Grass is Singing. London New York Toronto Sydney and New Delhi: Harper Perennial.

Perlmutter, David M.

1978 Impersonal passives and the unaccusative hypothesis. Proceedings of the Fourth Annual Meeting of the Berkeley Linguistics Society, 157-189. Berkeley: Berkeley Linguistic Society, University of California, Berkeley. 
Perlmutter, David M. \& Paul Postal

1984 The 1-advancement exclusiveness law. In: David M. Perlmutter and Carol G. Rosen (eds.), Relational Grammar 2, 81-125. Chicago: Chicago University Press.

Postal, Paul

1977 About a non-argument for raising. Linguistic Inquiry 8: 141-154.

Postal, Paul

2004 Skeptical Linguistic Essays. Oxford: Oxford University Press.

Prince, Ellen

1992 The ZPG Letter: Subjects, definiteness, and information-status. In: Sandra Thompson and William Mann (eds.), Discourse Description: Diverse Analyses of a Fundraising Text, 295-325. Amsterdam: John Benjamins.

Rochemont, Michael S.

1978 A theory of stylistic rules in English. PhD Dissertation. University of Massachusetts, Amherst.

Rochemont, Michael S.

1986 Focus in Generative Grammar. Amsterdam/Philadelphia: John Benjamins.

Rochemont, Michael S. and Peter W. Culicover

1990 English Focus Constructions and the Theory of Grammar. Cambridge/ New York: Cambridge University Press.

Salzmann, Martin

2009 Repair-driven verb movement in English locative inversion. In: Patrick Brandt and Eric Fuss (eds.), Repairs. Berlin: Mouton. 